\title{
Processos de autoria de objetos digitais como potenciais para aprendizagem
}

\author{
Juliano Tonezer da Silva ${ }^{1}$ \\ Vitor Malaggi ${ }^{2}$
}

\begin{abstract}
Resumo: O presente artigo apresenta uma metodologia de apoio ao processo de aprendizagem via autoria de objetos digitais por alunos, destacando a contribuição desta através de seus potenciais para aprendizagem. É uma extensão da metodologia de projetos de aprendizagem e está fundamentada na autoria de projetos de aprendizagem e de objetos de aprendizagem por alunos, sob orientação. Esta foi validada por meio de um processo de investigação na Escola MC. No artigo relata-se um dos objetos de aprendizagem produzidos, o "Rally dos Sertões".
\end{abstract}

Palavras-chave: Projetos de aprendizagem. Objetos de aprendizagem. Epistemologia genética.

\begin{abstract}
This article presents a learning process support methodology through authorship of digital objects by students, highlighting its contribution through their potential for learning. It is an extension of the learning projects methodology and is based on the authorship of learning projects and the learning objects by students, under supervision. This was validated through a process of research, in the school $M C$, where in the article reports one of the learning objects produced, the "Rally dos Sertões".
\end{abstract}

Keywords: Learning projects. Learning objects. Genetic epistemology

\section{Introdução}

As tecnologias digitais cada vez mais estão sendo inseridas no cotidiano das escolas públicas, provocando reflexões e a busca por iniciativas de apropriação plena destas por parte dos integrantes deste contexto. Como análise central, questiona-se se o ter acesso as tecnologias é suficiente para que ocorra uma potencialização dos processos educativos. Assim, novas metodologias de aprendizagem devem ser adotadas, imbricadas com as características e possibilidades abertas por estas tecnologias digitais, para que ocorra de fato a convergência entre educação e informática.

Com este intuito, este artigo busca analisar a união entre os projetos de aprendizagem e objetos de aprendizagem como uma metodologia que possibilita a participação dos envolvidos no processo de ensinoaprendizagem, em especial, os alunos e professores. Como contribuição da pesquisa e alternativa a esta problemática, foi proposta e validada uma metodologia de apoio ao processo de aprendizagem via autoria de objetos de aprendizagem por alunos. Por fim, são verificadas as contribuições desse processo na potencialização das aprendizagens nas áreas de Ciências e Matemática do Ensino Médio de uma turma de alunos da escola pública MC.

\footnotetext{
${ }^{1}$ Curso de Ciência da Computação, UPF, Campus 1 - BR 285 - Passo Fundo (RS) - Brasil

\{tonezer@upf.br\}

${ }^{2}$ Mestrando do Programa de Pós-Graduação em Educação (PPGEDU), na Universidade de Passo Fundo (UPF), Campus 1 BR 285 - Passo Fundo (RS) - Brasil

\{malaggi@gmail.com\}
}

doi: $10.5335 /$ rbca. 2009.008 
Enfim, a presente metodologia é uma extensão da metodologia de projetos de aprendizagem proposta por Fagundes (1999) e está fundamentada na autoria por alunos de projetos de aprendizagem e objetos de aprendizagem, na adoção de princípios ágeis como processo de autoria e num contexto escolar de aprendizagem com o apoio das tecnologias digitais.

\section{Aprendizagem segundo a epistemologia genética}

Na percepção de Piaget [1], os sujeitos são os próprios construtores do conhecimento, desempenhando papel ativo nesta construção, onde constantemente estão criando, recriando e testando suas teorias sobre o mundo. Em seu livro Epistemologia Genética afirma que

[...] o conhecimento não procede, em suas origens, nem de um sujeito consciente de si mesmo nem de objetos já constituídos (do ponto de vista do sujeito) que se lhe imporiam: resultaria de interações que se produzem a meio caminho entre sujeito e objeto, e que dependem, portanto, dos dois ao mesmo tempo [...].

Nessa ótica, a aprendizagem resulta das ações (interações) entre o sujeito/objeto, sendo o sujeito um ser ativo nesse processo, e depende também das construções e reconstruções dos sistemas de significação e sistemas lógicos de cada indivíduo. Nesse sentido, Piaget afirma que a ação é o instrumento da construção:

Para conhecer objetos o indivíduo deve agir sobre eles e, portanto, transformá-los, deve deslocá-los; ligálos, combiná-los, separá-los, desmontá-los e voltar a montá-los. Segundo Piaget [2], desde as mais elementares ações sensório-motoras até as mais refinadas operações intelectuais, que são ações internalizadas e executadas mentalmente, o conhecimento está constantemente ligado a ações ou operações, isto é, a transformações.

Com relação à aprendizagem, para Piaget e Gréco [3], existem sete formas (processos) de se adquirir conhecimento, sendo a aprendizagem (no sentido restrito - stricto sensu) uma delas, conforme pode ser observado na Tabela 1. Num sentido geral, "[...] a aprendizagem é um processo adaptativo se desenvolvendo no tempo, em função das respostas dadas pelo sujeito a um conjunto de estímulos anteriores e atuais". Porém, os autores distinguem a aprendizagem em duas abordagens: no sentido amplo (lato sensu) e no sentido restrito (stricto sensu).

Tabela 1. Processos de aquisição de conhecimentos

\begin{tabular}{|c|c|c|c|c|c|}
\hline \multirow{7}{*}{$\begin{array}{l}\text { Formação dos } \\
\text { conhecimentos } \\
\text { (desenvolvimento) }\end{array}$} & \multicolumn{4}{|c|}{ Hereditariedade } & 1) Maturação \\
\hline & \multirow{6}{*}{ Aquisição } & \multirow[b]{2}{*}{ Imediata } & Leitura & & 2) Percepção \\
\hline & & & $\begin{array}{l}\text { Interpretação sensório- } \\
\text { motora ou nocional (não } \\
\text { inteiramente dedutiva) }\end{array}$ & & $\begin{array}{l}\text { 3) Compreensão } \\
\text { Imediata e pré-operatória }\end{array}$ \\
\hline & & \multirow{4}{*}{ Mediata } & \multirow{2}{*}{$\begin{array}{l}\text { Em função } \\
\text { da experiência }\end{array}$} & Controle não sistemático & $\begin{array}{l}\text { 4) Aprendizagem } \\
\text { (sentido restrito) }\end{array}$ \\
\hline & & & & Controle não sistemático & 5) Indução \\
\hline & & & \multirow{2}{*}{$\begin{array}{l}\text { Não função } \\
\text { da experiência }\end{array}$} & Controle não sistemático & $\begin{array}{l}\text { 6) Coerência pré-operatória } \\
\text { (equilibrações) }\end{array}$ \\
\hline & & & & Controle sistemático & $\begin{array}{l}\text { 7) Dedução (e no caso extremo: } \\
\text { compreensão imediata operatória) }\end{array}$ \\
\hline
\end{tabular}

Fonte: Piaget e Gréco [3, p. 55]

No sentido restrito (Tabela 1, item 4), o termo "aprendizagem" fica reservado para a aquisição de conhecimento em função da experiência, ou seja, para Piaget e Gréco [3], "[...] aprendizagem na medida em que um resultado (conhecimento ou atuação) é adquirido em função da experiência, essa experiência podendo aliás ser do tipo físico ou lógico-matemática ou os dois [...]". Isso com a ressalva de que "[...] todo o resultado adquirido em função da experiência não constitui uma aprendizagem".

No sentido amplo (Tabela 1, itens $4+6$ ), refere-se às aprendizagens que não se devem somente à experiência, ou seja, segundo Piaget \& Gréco [3] "[...] aquisições devidas a um processo dedutivo", no qual "é a 
partir do nível operatório (7-8 anos) que a dedução constitui assim uma fonte de aquisições independentes da experiência". Indo além, os autores delimitam que "é aqui que colocaremos as aquisições dependendo dos processos de equilibração [...], mas de nível pré-operatório (o equilíbrio completo atingindo a dedução)", ou seja, "designaremos pelo termo 'coerência pré-operatória' essas aquisições devidas a um processo de equilibração distinto de uma aprendizagem no sentido restrito". Assim, "[...] chamaremos 'aprendizagem no sentido amplo (s. lat) [latu sensu]' à união das aprendizagens s. str. [(strictu sensu, sentido restrito)] e desses processos de equilibração".

Por meio dos processos de equilibração, Piaget [4] busca explicar "[...] o desenvolvimento e mesmo a formação do conhecimento". Equilibração "[...] que conduz de certos estados de equilíbrio aproximados a outros, qualitativamente diferentes, passando por múltiplos desequilíbrios e reequilibrações". Ainda, a equilibração resulta de dois processos complementares: assimilação e acomodação. Nas palavras de Piaget, "[...] dois processos fundamentais que constituirão os componentes de todo o equilíbrio cognitivo. O primeiro é a assimilação [...]. O segundo [...] é a acomodação" [3]

Nesse sentido, o processo de assimilação é a "[...] incorporação de um elemento exterior (objeto, acontecimento, etc.) em um esquema sensorimotor ou conceitual do sujeito" [4]. Este pode ser entendido como o processo de classificar novos elementos (objetos, acontecimentos, etc.) em esquemas preexistentes. Assim, no processo de assimilação o elemento exterior, se assimilado, passa a integrar a estrutura cognitiva (esquemas) que o sujeito já possui.

Já o processo de acomodação é "[...] a necessidade em que se acha a assimilação de levar em conta as particularidades próprias dos elementos a assimilar" [4]. Pode-se entender que o processo de acomodação é uma estruturação de esquemas de assimilação em função das particularidades do elemento exterior (objeto, acontecimento, etc.), através de duas possibilidades: criação de um novo esquema ou modificação de um esquema já existente. Entretanto, é pertinente entender que, para Piaget [3], "[...] a assimilação e acomodação constituem dois pólos sempre inseparáveis e não duas condutas distintas" e que o movimento de equilíbrio entre a assimilação e acomodação é denominado de adaptação.

Outro aspecto no processo de construção do conhecimento, essencial para a pesquisa em questão, é a formação dos "possíveis", ou abertura para novos possíveis, conceito pelo qual Piaget procurou defender sua posição construtivista.

Para justificar nossa epistemologia construtivista contra o inatismo ou o empirismo, não é suficiente mostrar que todo conhecimento novo resulta de regulações, de uma equilibração, pois sempre se poderá supor que mesmo o mecanismo regulador é hereditário, ou, ainda, que resulta de aprendizagens mais ou menos complexas. Procura-se, por isso, abordar o problema da produção de novidades de outro modo, centrando as questões na formação dos 'possíveis'.

Para Piaget, o possível "[...] não é algo observável, mas o produto de uma construção do sujeito, em interação com as propriedades do objeto" [5]. Como complemento, Nevado [6] descreve:

As propriedades ou as características do objeto são interpretadas devido às atividades do sujeito, que determinam o nascimento de novos possíveis e um enriquecimento das interpretações do sujeito. O possível cognitivo é essencialmente criação e invenção.

Porém, é importante destacar que o interesse de Piaget com relação aos problemas do possível não é apenas o seu aspecto dedutível, mas, sim, "[...] o processo de formação das possibilidades, ou seja, a 'abertura' para os novos possíveis que o sujeito descobrirá por si mesmo". Assim, afirma que "é esse de fato o problema central da epistemologia construtivista: o da construção ou criação do que existia apenas em estado virtual do 'possível' e que o sujeito deverá atualizar" [7]. Para Nevado [6]:

Qualquer inovação apresentada por um sujeito, ao atualizar-se, transforma-se num esquema de procedimentos, que tenderá a alimentar-se, aplicando-se a situações análogas. Essa generalização possível do esquema de procedimento confere ao sujeito um novo poder, que ao exercer-se levantará novos problemas (sejam esses impostos pelo meio ou resultado da própria necessidade interna de atividade desencadeada pelos êxitos anteriores). 
Para Piaget [5], um êxito é decorrente de dois efeitos contrários: uma novidade criadora e uma lacuna virtual. Portanto, a atividade cognitiva humana consiste em contínuas superações e inovações, de modo que a cada problema solucionado outros novos são propostos. Portanto, do ponto de vista da invenção, para [7] um erro corrigido por regulações "[...] pode ser mais fecundo que um êxito imediato, porque a comparação da hipótese falsa e suas conseqüências proporcionam novos conhecimentos e a comparação entre erros dá lugar a novas idéias". Entretanto, Nevado informa que para obter novos possíveis não é suficiente apenas "[...] imaginar processos (ou procedimentos) que visam a um determinado objetivo, mas também compensar as perturbações (obstáculos) efetivas ou virtuais (pseudonecessidades) que limitam e refreiam esse desenvolvimento" [6]. Desse modo, nas ocasiões em que o sujeito supera alguma barreira do real, "[...] ele pode concluir, por meio de inferências, que se uma variação ou uma modificação é possível, outras também serão" [6].

Também afirma Piaget [7] que a formação dos novos “possíveis” está subordinada a duas condições: (1) constituição de livres combinações entre os dados ou o contexto de um problema não resolvido e os procedimentos empregados ou experimentados para resolvê-los; (2) uma seleção entre as combinações, destinadas a corrigir os erros, em razão dos resultados obtidos pelos procedimentos (seleção exógena), ou em razão dos esquemas já organizados (seleção endógena).

Por fim, destaca-se que para ocorrer a aprendizagem, segundo a epistemologia genética, os sujeitos devem desempenhar papel ativo na construção de seus conhecimentos, criando, recriando e testando suas teorias sobre o mundo e em busca constante de novos possíveis.

\section{Projetos de Aprendizagem}

A ideia de estabelecer um método de ensino que se baseasse no desenvolvimento de projetos, visando à descoberta e à pesquisa de problemas relevantes aos interesses do sujeito aluno, nasceu no interior do Movimento de Renovação Pedagógica ou Escola Nova. A acepção "Escola Nova” surge, primeiramente, como uma forma de rotular os estabelecimentos de ensino que procuraram, a partir dos anos finais do séc. XIX, transformar as práticas e normas tradicionais de organização escolar. Posteriormente, segundo Lourenço Filho, a expressão veio a "[...] adquirir mais amplo sentido, ligado ao de um novo tratamento dos problemas da educação, em geral" [8], ou seja, visava sintetizar uma série de princípios, objetivos e propostas pedagógicas deste movimento, o qual agregava em seu interior pensadores de diversas matizes teóricas e as suas respectivas ideias sobre a educação, como John Dewey, William Kilpatrick, Celestin Freinet, Maria Montessori, Óvide Drecoly, Edouard Claparède, Roger Cousinet e Adolphe Ferriére.

Ao mesmo tempo em que abarcava propostas diferenciadas, este movimento manteve uma unidade e consistência derivada de uma série de objetivos gerais unificados, por meio dos quais todos os participantes e teóricos da Escola Nova propunham suas ideias. Para Barbosa [9], é possível delimitar alguns destes pontos em comum:

[...] - a crítica à escola tradicional - aos seus conteúdos pré-programados, hierarquizados e dissociados da realidade dos alunos e aos seus métodos de ensino ultrapassados;

- a construção de uma concepção de criança e de aprendizagem distinta da tradicional;

- a crítica ao trabalho escolar que era feito para a escola e não para a aprendizagem e a formação da criança;

- a organização de experiências pedagógicas alternativas;

$[\ldots]$

- as sugestões para a reorganização do espaço da sala de aula e dos tempos de trabalho escolar;

- a proposição de novas formas de organização do ensino;

$[\ldots]$

- a crítica a uma escola que tinha as lições como centro da rotina escolar;

- a utilização do método científico na escola (observação, hipótese, verificação, conclusão ou lei geral). 
Como princípio fundamental do movimento da Escola Nova pode-se destacar a crítica ao ensino então vigente. Assim, Snyders pontua que "[...] a educação nova toma como ponto de partida as decepções e lacunas que se apresentavam como características da educação tradicional" [10]. Portanto, primeiramente se faz necessário situar as seguintes questões: o que vem a ser a educação tradicional? O que a caracteriza e o que pretende como uma proposta teórica e prática de educação? Embasando-se em autores como [11], [10] e [12], é possível afirmar que o objetivo maior da escola tradicional é transmitir aos alunos um conjunto de conteúdos de ensino que os habilitem a ocupar futuramente um lugar na sociedade existente. No que tange às características desta teoria educacional, é possível delimitar algumas ideias que ajudam na conceitualização e na compreensão das propostas do ensino ou escola tradicional:

a) a opção por uma escola voltada para a transmissão artificial dos "modelos", ou seja, os conteúdos ligados às áreas mais desenvolvidas do conhecimento humano e que deveriam ser assimilados pelos alunos, através de uma graduação linear e hierarquizada;

b) a cisão da realidade e da vida do aluno com os objetivos da escola como pressuposto para uma educação livre das angústias, misérias e incertezas da realidade;

c) a centralização do professor como principal peça do ato educativo;

d) uma visão de criança como adulto em miniatura, que desconsidera toda a singularidade deste período;

e) um método de ensino que tem como pressuposto epistemológico a transmissão dos conteúdos para a mente dos aprendizes;

f) uma forma de organização de espaço-tempo que desconsidera as singularidades existentes em sala de aula, homogeneizando e padronizando o ensino para todos.

Assim, historicamente, a Escola Nova pode ser vista e compreendida como um movimento educacional que objetivou dar uma interpretação diferenciada da escola tradicional acerca de pontos teóricos e práticos importantes do processo educativo. Recobrar e refletir criticamente sobre os posicionamentos educacionais da Escola Nova é de suma importância, visto que formaram um conjunto de questionamentos coerentes acerca de supostos aspectos negativos advindos das concepções tradicionais de ensino e que, portanto, contribuem para a evolução do debate educacional.

Nesse sentido, diversos fluxos de interesse pelo desenvolvimento de um sistema didático baseado em projetos foram sendo delimitados ao longo do século XX. Estas ressignificações visavam apropriar-se das contribuições teóricas iniciais de Dewey e da Escola Nova, porém dando alguns novos direcionamentos para questões pontuais dentro desta temática. Conforme Hernández [13], um desses fluxos de interesse surgiu a partir da metade dos anos 60, com o nome de "trabalho por temas", no qual a pergunta basilar foi: "[...] que conceitos ensinamos e com que critérios os selecionamos?". Nesses termos, o principal pesquisador deste novo fluxo de interesse por projetos foi Jerome Bruner (1915- ), influenciado por trabalhos de Hilda Taba (1904-1967) e Lawrence Stenhouse (1926-1982), que defendia a figura do professor-pesquisador e a docência como aprendizagem.

Um terceiro momento, no qual os projetos voltam a ser objeto de interesse foi influenciado por dois acontecimentos que marcaram a prática dos projetos nos anos 80: (i) a revolução cognitiva, desencadeada pelos estudos de Jean Piaget (1896-1980), que pesquisou sobre a maneira como se pensava a aprendizagem e a aquisição dos conhecimentos; (ii) o saber decorrente das Tecnologias Digitais de Rede (TDRs). Neste fluxo surgem novas reinterpretações do termo "pedagogia de projetos", por pesquisadores como Léa Fagundes (projetos de aprendizagem), Fernando Hernández (projetos de trabalho), Josette Jolibert (projetos referentes à vida cotidiana, projetos empreendimentos e projetos de aprendizado), entre outros.

Advindo deste contexto de ressignificações do uso de projetos na educação, surge o termo "projeto de aprendizagem", ou metodologia de projetos de aprendizagem, já testada por meio de processos de pesquisa como o EducaDi/CNPq (1997/1998) e descrita no livro Aprendizes do Futuro: as inovações começaram [14]. Esta ressignificação tem origem no fato de que o objetivo maior a ser perseguido é a aprendizagem dos conceitos, construídos por meio do ato de projetar.

Um projeto de aprendizagem (PA) inicia-se pela escolha de um tema, que não precisa ser um assunto, mas um problema para o qual se busca uma solução. Problematizar o tema de pesquisa torna-se uma prática extremamente recomendável, pois é a partir de um problema que será possível verificar o conhecimento prévio do aluno sobre o assunto, o qual levantará melhor e com mais facilidade suas hipóteses sobre o tema/problema, o 
que resultará numa posterior facilidade para a confrontação e relacionamento das informações conseguidas pó meio da pesquisa.

Assim, nesta metodologia os projetos são iniciados pelas certezas provisórias e dúvidas temporárias dos aprendizes, vinculando-as aos seus saberes prévios. Essas certezas correspondem àquilo que naquele determinado momento da aprendizagem os alunos tomam como verdade sobre um assunto. As dúvidas são o que eles gostariam de aprender a mais sobre o assunto. Segundo Fagundes [14], nada impede, e provavelmente irá ocorrer, que no percurso dos projetos "[...] muitas dúvidas tornam-se certezas e certezas transformam-se em dúvidas; ou, ainda, geram outras dúvidas e certezas que, por sua vez, também são temporárias, provisórias".

Após a definição do tema/problema, certezas provisórias e dúvidas temporárias, parte-se para o desenvolvimento do projeto de aprendizagem por meio de pesquisas e busca de informações. Não é objetivo de um projeto de aprendizagem fazer com que o aluno apenas copie informações, o que não modificaria o enfoque transmissivo praticado em sala de aula. Segundo Fagundes [14], "[...] buscar a informação em si, não basta. É apenas parte do processo para desenvolver um aspecto dos talentos necessários ao cidadão. Os alunos precisam estabelecer relações entre as informações e gerar conhecimento". Também é necessário que a busca de informações seja produto das ações dos alunos, em conjunto com o professor, não somente das decisões do docente. Assim, os alunos vão adquirindo competência e autonomia para selecionar o que é importante e descartar o que é supérfluo

O aluno, ao realizar uma comparação entre a informação da pesquisa e o que anteriormente definia como uma certeza ou dúvida, estará criando as situações para que o conhecimento e as redes de significações sejam expandidos, bem como desenvolvendo a sua capacidade de pesquisa e problematização de temas, visto que nestes momentos em específico podem ocorrer os conflitos cognitivos. Resumidamente, esse entendimento sobre a construção de conhecimento advindo da teoria piagetiana pode ser compreendido nas seguintes palavras de Fagundes [14]:

Para que um novo conhecimento possa ser construído, ou para que o conhecimento anterior seja melhorado, expandido, aprofundado, é preciso que um processo de regulação comece a compensar as diferenças, ou as insuficiências do sistema assimilador. Ora, se o sistema assimilador está perturbado é porque a certeza 'balançou'. Houve desequilíbrio. O processo de regulação se destina a restaurar o equilíbrio, mas não o anterior.

$\mathrm{Na}$ verdade, trata-se sempre de um novo equilíbrio, pois o conhecimento melhora e aumenta! E, justamente é novo, porque é um equilíbrio que resultou da assimilação de uma novidade e, portanto, da ampliação do processo de assimilação do sujeito, que se torna mais competente para assimilar novos objetos e resolver outros novos problemas.

Nesses termos, os projetos de aprendizagem propostos buscam, antes de tudo, a construção e reconstrução permanentes do conhecimento pelo aluno, oportunizando, assim, os momentos em que os discentes realizarão tarefas cognitivas diversas que os habilitem a compreender o objeto de conhecimento delimitado no âmbito de sua pesquisa. Por fim, a atividade de desenvolvimento de um PA pode, ainda, agregar momentos de avaliação das conquistas efetivadas pelos alunos; esses espaços de socialização devem sempre propor um contexto avaliativo de todos os processos educativos ocorridos, não somente os produtos finais da pesquisa, buscando, assim, redirecioná-la quando necessário.

\section{Objetos de Aprendizagem}

Os objetos de aprendizagem (OAs), na área de informática na educação, estão sendo apontados como uma das principais tendências tecnológicas educacionais, pois possibilitam, pelas suas características, conferir ao processo de aprendizagem um caráter interativo, dinâmico, flexível e motivador.

Por ser uma área de domínio técnico e científico que vem sendo estudada e pesquisada há pouco tempo, se comparada a outras áreas da computação e da informática na educação, diversas são as definições ou 
concepções sobre o que vem a ser um objeto de aprendizagem. Assim, diversas áreas do conhecimento (educação, computação, psicologia, etc), autores, pesquisadores, consórcios e instituições vêm definindo seus próprios conceitos, não existindo ainda um consenso sobre sua conceituação teórica e nomenclatura.

Apesar da dificuldade de validar por quem e quando o termo "objetos de aprendizagem" foi utilizado inicialmente, alguns autores creditam a Wayne Hodgins, no ano de 1994, uma primeira utilização do termo. Segundo Wiley [15] e Ritzhaupt [16], é provável que o autor do termo tenha sido mesmo Wayne Hodgins, que o utilizou pela primeira vez em 1994 "[...] no título do grupo de trabalho do CEDMA chamado 'Arquiteturas de Aprendizagem, API's e Objetos de Aprendizagem"' [15]. Nesse contexto, Ritzhaupt cita um acontecimento no qual Wayne Hodgins teria concebido o termo: "[...] Hodgins estava vendo seu filho construir coisas com o LEGO ${ }^{\circledR}$ enquanto pensava sobre estratégias de aprendizagem" [16]. Nesse momento Hodgins imaginou construir blocos de aprendizagem interoperáveis, como as peças do LEGO ${ }^{\circledR}$, para apoiar a aprendizagem, os quais ele nomeou de "objetos de aprendizagem". Este acontecimento também pode ser verificado, em partes, em [17].

Relacionados à conceituação do termo "objetos de aprendizagem” encontram-se vários conceitos, alguns baseados nas suas propriedades e características; outros, nos elementos que o compõem. Entre os conceitos mais citados em artigos e trabalhos científicos aparecem os de entidades e consórcios como o do $\mathrm{LTSC}^{3} / \mathrm{IEEE}^{4}$; o do Wisconsin On-line Resource Center e da Cisco System e de pesquisadores como David Wiley e James L'Allier.

Para o Comitê de Padrões para Tecnologias de Aprendizagem (LTSC) do IEEE, “[...] um Objeto de Aprendizagem é definido como qualquer entidade - digital ou não-digital - que pode ser usada [reusada ou referenciada] para aprendizagem, educação e treinamento" [18]. Ainda segundo o LTSC, podem ser considerados objetos de aprendizagem "[...] conteúdos multimídia, conteúdos instrucionais, objetivos de aprendizagem, software instrucionais, e até pessoas, organizações ou eventos" [15]. Deste conceito se destaca de o fato de LTSC considerar os objetos de aprendizagem também como entidades nãodigitais.

A Wisconsin On-line Resource Center define os objetos de aprendizagem como sendo "[...] uma nova forma de pensar sobre a aprendizagem de conteúdos [...] que são segmentos de aprendizagem muito menores que cursos, módulos ou unidades" [19]. Isso foi definido em razão das características que um OA deve apresentar, segundo a Winconsin: autônomos, interativo, não-interativo, reutilizável, descartáveis e agrupáveis.

Para Wiley [15] um objeto de aprendizagem é “[...] qualquer recurso digital que pode ser reusado para suportar a aprendizagem", embasado no paradigma orientado a objetos da ciência da computação, que prevê a criação de objetos que podem ser reusados em diferentes contextos. Nesses termos, para Wiley [20], "a idéia fundamental por trás dos objetos de aprendizagem: projetistas educacionais podem construir pequenos componentes educacionais (relativo ao tamanho de um curso inteiro) que podem ser reusados várias vezes em diferentes contextos de aprendizagem". Ainda, esta tecnologia educacional "[...] inclui tudo que pode ser distribuído pela rede sob demanda, seja isto grande ou pequeno". Para este autor, recursos digitais pequenos podem ser fotos, vídeos ao vivo ou gravados, áudio, animações, aplicações web ("como uma calculadora Java"), etc. Como recursos digitais grandes podem ser citados os exemplos das páginas web, as quais combinam diversos elementos de mídias menores, como textos, imagens, sons, etc. Enfim, Wiley [15] justifica que seu conceito de OA é suficientemente pequeno para definir razoavelmente o conjunto dos recursos digitais reusáveis e que está embasado na definição do LTSC/IEEE. Este conceito também é adotado, por exemplo, pelo RIVED.

Outros pesquisadores buscam definir um objeto de aprendizagem com base nos elementos que o compõem. Assim, L'Allier [21] o define “[...] como a menor experiência educacional autônoma que contém um objetivo, uma atividade de aprendizagem e uma avaliação". Nesse contexto, um OA pode ser definido por meio de três elementos: (1) o objetivo ou propósito para o qual foi construído, quais conteúdos ou conhecimentos pretende-se construir com o aluno através do uso do OA; (2) a atividade de aprendizagem: interação entre o aluno e o OA, através da qual serão construídos os conhecimentos; (3) a avaliação: verificação do que foi compreendido pelo aluno. Percebe-se que nesta definição aparecem, além dos elementos que compõem o OA, outras características, tais como a autonomia do OA e a interatividade.

Neste artigo, em específico, adotou-se a acepção de Wiley [15] “[...] qualquer recurso digital que pode ser reusado para suportar a aprendizagem", destacando-se também os seguintes pontos de sua concepção: (1) a exclusão da conceituação dos OAs às entidades nãodigitais; (2) a referência explícita às características de

\footnotetext{
${ }^{3}$ Learning Technology Standards Committee

${ }^{4}$ Institute of Electrical and Electronics Engineers
} 
reutilização (excluindo os não-reutilizáveis), granularidade e agrupabilidade (combinação); (3) os OA podem apresentar diversos tamanhos (pequenos ou grandes), bem como podem ser agrupados entre si para compor diferentes níveis estruturais entre os OAs; (4) ênfase na utilização dos OAs para suporte a aprendizagem.

Além dessas, várias outras características são atribuídas aos OAs, no sentido de auxiliar na sua compreensão conceitual. Destacam-se, quatro das mais citadas - mesmo não existindo um consenso sobre esta escolha - oriundas de pesquisas de diversos autores e/ou entidades: reusabilidade, agregação, identificação por metadados e interatividade.

A reutilização ou reusabilidade, que está na gênese da ideia dos OAs, é a construção de segmentos de aprendizagem na forma computacional, os quais podem ser reutilizados em diversos contextos ou situações de aprendizagem. A reusabilidade também se "conecta" com outras características dos OAs, como, por exemplo, a granularidade e a modularidade. Com relação à granularidade (tamanho do OA), Wiley [20] e The Masie Center [22] pontuam que, quanto menor for a granularidade de um OA, ou seja, quanto mais pequeno e "bruto" for o estado de seu conteúdo, maior será a sua capacidade de reutilização em um outro contexto de aprendizagem ou mesmo em outro OA. No que se refere à modularidade, pode-se dizer que, quanto mais modular for o OA, ou seja, quanto mais fácil for seccionar suas "peças" ou componentes (textos, imagens, animações, sons) do todo, maior será a capacidade de reutilizar e recombinar essas peças em outros contextos e/ou OA.

A agregação é a característica que um OA possui de ser agregado, agrupado, combinado com outros OA, formando, assim, estruturas de aprendizagem compostas de diversos OA, com diferentes tamanhos (granularidade). Estes OAs, ao serem combinados, tornam-se mais complexos e contextualizados com uma determinada situação ou objetivo de aprendizagem, bem como sua granuralidade aumenta. Unindo diversos OAs, podem-se construir desde estruturas simples de conteúdos, como uma aula em particular, a coleções complexas de informações inter-relacionadas, tais como a demonstração de conteúdos de um curso inteiro. A característica de combinação dos OAs depende muito de outras propriedades destes, tais como a reusabilidade e a modularidade, pois, quanto maior for a reusabilidade, mais fácil será agregar outros OAs a um já existente. Também se torna mais fácil agregar um OA a outro se o sistema for modular, ou seja, fácil de ser decomposto para após ser feita uma nova coesão das peças formadoras com o novo OA.

A identificação por metadados permite armazenar em arquivos digitais informações relevantes sobre o OA, tais como o autor do recurso, passando pela data de sua criação, qual a sua finalidade, para que públicoalvo, etc. Esses metadados, posteriormente, serão de extrema utilidade para a localização e combinação dos OA através da internet e de sistemas de gerenciamento de objetos de aprendizagem. Em síntese, os metadados, ou "dados sobre dados", são, segundo Wiley [20], "[...] informações descritivas sobre um recurso", ou seja, são informações que descrevem informações importantes sobre algum recurso, de acordo com um contexto. Essas informações variam desde o autor do recurso, passando pela data de sua criação, qual a sua finalidade, para que público-alvo, ou qualquer outra informação que se julgue necessária.

A interatividade é a propriedade que pressupõe o que o usuário/aprendiz que fará uso dos OAs deve encontrar nestes meios para interagir com os conceitos abordados neste.

Em grande parte dos objetos de aprendizagem desenvolvidos e disponibilizados em repositórios on-line essa interação entre o aprendiz e o objeto de estudo se dá pela leitura visual de imagens, textos, animações e escuta de partes sonoras, que descrevem uma determinada situação, fato ou conceito ao aprendiz. Nessas situações, pode estar ocorrendo algum tipo de interação, porém de maneira "superficial", pois o aprendiz não está atuando, não está interagindo com o objeto de estudo; está apenas escutando ou assistindo "passivamente" ao "desenrolar" de explicações sobre os conteúdos tratados no OA. Do ponto de vista da área da computação denomina-se esta de interação expositiva.

Entretanto, um OA que pressupõe uma atividade de aprendizagem, uma ação efetiva por parte do estudante, deve permitir-lhe interagir em níveis mais elevados e complexos com os conceitos e com o objeto de estudo. Assim, o aprendiz, ao pensar, refletir e interagir com os conceitos abordados através do OA, poderá aplicá-los posteriormente na resolução da situação/problema, atuando sobre o objeto de conhecimento em questão em níveis cognitivos e interativos mais elevados, e poderá com sua ação construir e/ou reconstruir o(s) conhecimento(s) inerentes ao objeto de estudo de maneira mais eficaz. Enfim, do ponto de vista da área da computação, esta seria uma interação do tipo ativa.

Nesse sentido, o LTSC [18] apresenta três tipos de interação, ou seja, modos predominantes de aprendizagem suportada por um objeto de aprendizagem: ativa, expositiva e mista. A interação ativa remete a 
ações produzidas pelos alunos, como por exemplo, aprender fazendo, ao passo que a interação expositiva (passiva) consiste em o aluno "aprender" o conteúdo exposto a ele. Por fim, a interação mista seria a combinação de ambas. Ainda, para esses tipos de interação o LTSC identifica cinco níveis de interatividade (muito baixo, baixo, médio, alto e muito alto), que possibilitam ao aluno a interação com as funcionalidades do objeto de aprendizagem.

\section{$5 \quad$ Metodologia de apoio ao processo de aprendizagem}

A proposição de uma metodologia de auxílio ao processo de aprendizagem para as áreas de ciências e matemática do ensino médio por meio da autoria de objetos de aprendizagem por alunos teve seu desenvolvimento a partir de pesquisa exploratória em escolas públicas pertencentes à $25^{\mathrm{a}}$ CRE-RS. [23], [24]. Esta metodologia foi validada através de um processo de investigação na Escola MC, que consistiu na autoria de projetos e de objetos de aprendizagem por alunos.

A estrutura geral da metodologia é apresentada a seguir, na forma de itens, porém não representa um processo sequencial, nem que todos os itens citados sejam obrigatórios. Portanto, durante a autoria de objetos de aprendizagem, o aluno não necessita perpassar todas as etapas, tampouco seguir a sequência como elas estão apresentadas.

Estrutura geral da metodologia

- Concepção do Objeto de Aprendizagem:

- (1) Representação textual;

- (2) Representação gráfica

- Autoria de Objetos para Aprender

- Projeto de Objetos para Aprender:

- (1) Roteiro de Tela;

- (2) Especificação de Requisitos;

- (3) Planejamento de tarefas

- Desenvolvimento de Projetos de Aprendizagem:

- (1) Concepção;

- (2) Execução;

- (3) Resultado(s)

- Programação: autoria de

- (1) programas;

- (2) interfaces gráficas

- Publicação do Objeto de Aprendizagem

- Identificação por metadados

- Publicação em repositório on-line

Resumidamente, a fase de concepção do $O A$ se faz necessária para registrar o momento de sua criação, por meio de uma representação textual e gráfica do OA. A fase de autoria de objetos para aprender pode desencadear três etapas não sequenciais, mas inter-relacionadas: (1) projeto dos OAs; (2) desenvolvimento de projetos de aprendizagem; (3) programação (de programas ou interfaces gráficas). O ponto de partida para a autoria de objetos para aprender é a etapa 1, de projetos por meio de ciclos de interação. A possibilidade de as etapas 2 e 3 ocorrerem estará associada as especificações dos requisitos definidos a partir dos roteiros de tela.

Um ciclo de interação, nesse contexto, é a conclusão de um roteiro de tela. A proposta é a criação do roteiro tela a tela (projeto tela a tela), não do roteiro na íntegra (projeto de todo o OA), isto é, projeta-se um roteiro de tela inicial (início do ciclo), efetuam-se as interações (quantas forem necessárias) e conclui-se a tela (fim do ciclo). Somente após concluir uma tela (roteiro de tela) é que se faz o projeto de um novo roteiro de tela inicial e assim sucessivamente. O objetivo principal com esta proposição é que o processo de aprendizagem dos alunos é prioridade em relação ao "produto final" (objeto de aprendizagem).

O processo de investigação, de validação da metodologia e análise do processo de produção dos objetos de aprendizagem pelos alunos da Escola MC ocorreu no ano de 2007. Esta fase da pesquisa, entre as ações necessárias à sua realização e as produções dos alunos, compreendeu o período de junho a novembro de 2007 , 
tendo sido realizada no turno inverso (tarde), nas terças-feiras e sextas-feiras, das $13 \mathrm{~h}$ e $30 \mathrm{~min}$ às $15 \mathrm{~h}$ e $30 \mathrm{~min}$, com alunos do primeiro ano do ensino médio.

A discussão e análise do processo de autoria das produções dos alunos foram subsidiadas por "potenciais para aprendizagem", que significam, no contexto desta pesquisa, indicativos de aprendizagem. O termo "potenciais para aprendizagem" é apresentado nesta pesquisa em decorrência do suporte teórico adotado, pelo qual a aprendizagem, segundo a epistemologia genética, engloba, entre outros, fatores como o conhecimento como resultante de interações entre sujeito e objeto; o sujeito desempenhando papel ativo - através da ação - na construção de seu conhecimento; a aprendizagem é dependente das construções e reconstruções dos sistemas de significação e sistemas lógicos do indivíduo; a atividade cognitiva humana consiste em contínuas superações e inovações, de modo que a cada problema solucionado outros são propostos [1], [2], [3], [4], [6] e [26].

Como potenciais para aprendizagem foram considerados no contexto da pesquisa os seguintes: os projetos de aprendizagem (PAs) definidos pelos alunos; projetos de aprendizagem possíveis de serem realizados (PAs em potenciais); a concepção de objetos de aprendizagem; os projetos de roteiros de tela; especificações de requisitos; programação de scripts; autoria de interfaces gráficas; os observáveis ${ }^{5}$ do sujeito; os possíveis $\operatorname{lógicos}^{6}$; as interações entre sujeitos: aluno-programador, aluno-professor, aluno-aluno, programador-professor, professor-professor.

Enfim, foram organizados sete grupos de alunos, que desenvolveram seus projetos de aprendizagem. Destes, podem-se considerar três como objetos de aprendizagem (versões funcionais), dois com autoria de scripts e interface e os outros dois com apenas roteiros de tela. Exemplificando a validação da metodologia e sua contribuição, descrevem-se brevemente situações do projeto "Rally dos Sertões", que gerou o processo de produção do objeto de aprendizagem "OA Rally dos Sertões", envolvendo os alunos ART e GAB.

O projeto Rally dos Sertões, que gerou o processo de produção do objeto de aprendizagem de mesmo nome, foi proposto pelos alunos ART e GAB. A intenção deste grupo foi realizar uma simulação de um rally onde o usuário (na condição de piloto do veículo) deveria passar por obstáculos em terra, água, etc. $\mathrm{O}$ usuário poderia escolher entre três tipos de veículos.

A representação textual da Concepção deste Objeto de Aprendizagem ocorreu conforme a sinopse abaixo, transcrita do documento 1 deste grupo de alunos:

\section{Rally dos Certões (sic) \\ No rally dos certoes (sic) o piloto passa-ra (sic) por obstáculo em terra, o piloto que terminar na frente ganhara. \\ Sera (sic) dividida em 3 categoria (sic): jepe, carro, moto. Passa-ra em diversos lugares e diferentes pistas. \\ Observações: o piloto pode escolher a categoria. O usuário poderá controlar o veiculo durante o percurso.}

O primeiro roteiro de tela (rs.rt017), conforme a Figura 1, deste objeto de aprendizagem apresenta imagens de carros como plano de fundo, para representar os veículos que participam em Rally's. Além das imagens, constam também os botões de acesso às opções deste OA.

\footnotetext{
5 "Aquilo que a experiência permite comprovar em uma leitura imediata dos fatos presentes por si mesmos".

${ }^{6}$ Para Piaget, o possível "não é algo observável, mas o produto de uma construção do sujeito, em interação com as propriedades do objeto" [1]. Ou seja, as "diversas circunstâncias reais ou hipotéticas que derivem de uma situação concreta de forma possível ou necessária".

7 "rs" significa Rally dos Sertões e "rt" roteiro de tela
} 


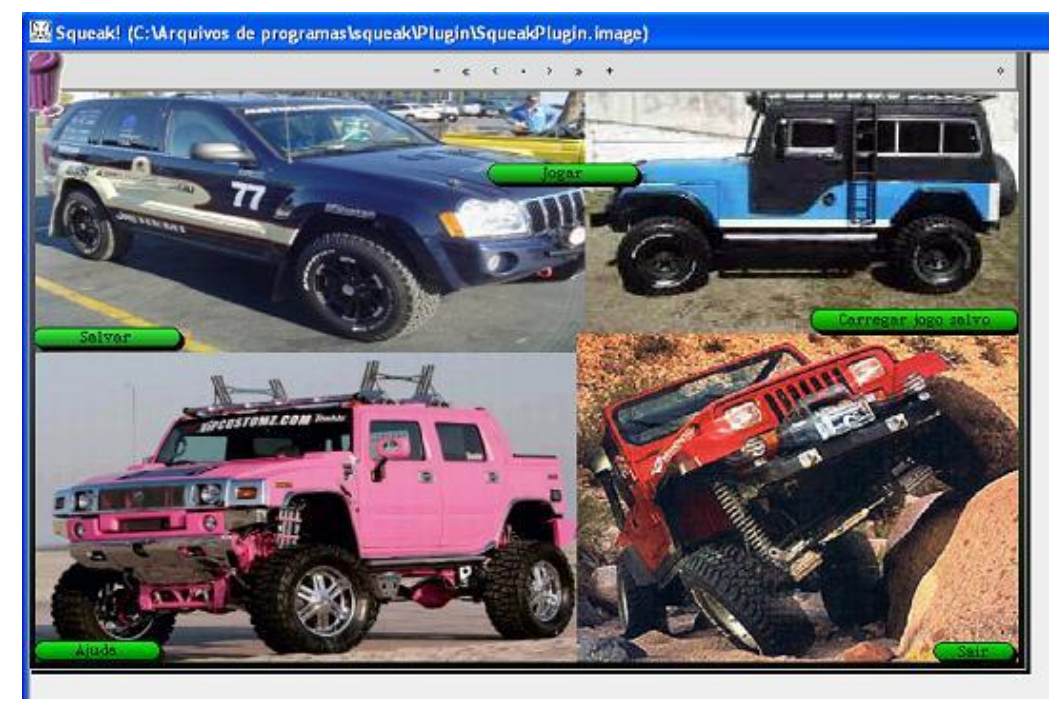

Figura 1. OA Rally dos sertões: roteiro de tela 01

Após análise da proposta pelos programadores e pesquisador, foi alertado aos alunos sobre o nível de dificuldade e o tempo demasiado que esta demanda iria exigir. Então, em decisão conjunta com os alunos, optouse por realizar uma versão simplificada, em uma pista circular, com vista aérea, para simular umas das pistas de rally que eles desejavam e relatadas no roteiro de tela 03 .

$\mathrm{O}$ roteiro de tela 03 (rs.rt03), conforme a Figura 2, apresenta novidades em relação à utilização de outros objetos, tais como: o Gerenciador de scripts (Suprimentos -> Todos os Scripts), que apresenta os botões stop (parar), step (passo-a-passo), go (ir) e, quando arrastado para o mundo, já carrega todos os scripts da cena em questão, permitindo o controle dos scripts; o Joystick $^{8}$ (Suprimentos -> Joystick), que permite o controle direcional da movimentação de um objeto, no caso, o carrinho. Os movimentos do objeto, nesta pista, através do Joystick, são definidos pelo evento "gira de" do objeto carrinho (carrinho -> gira de), associado à propriedade leftRight (esquerda - direita) do Joystick (Joystick -> leftRight). A pista, o gramado, o lago, o carrinho e a sinaleira são objetos desenho criados pelos alunos.

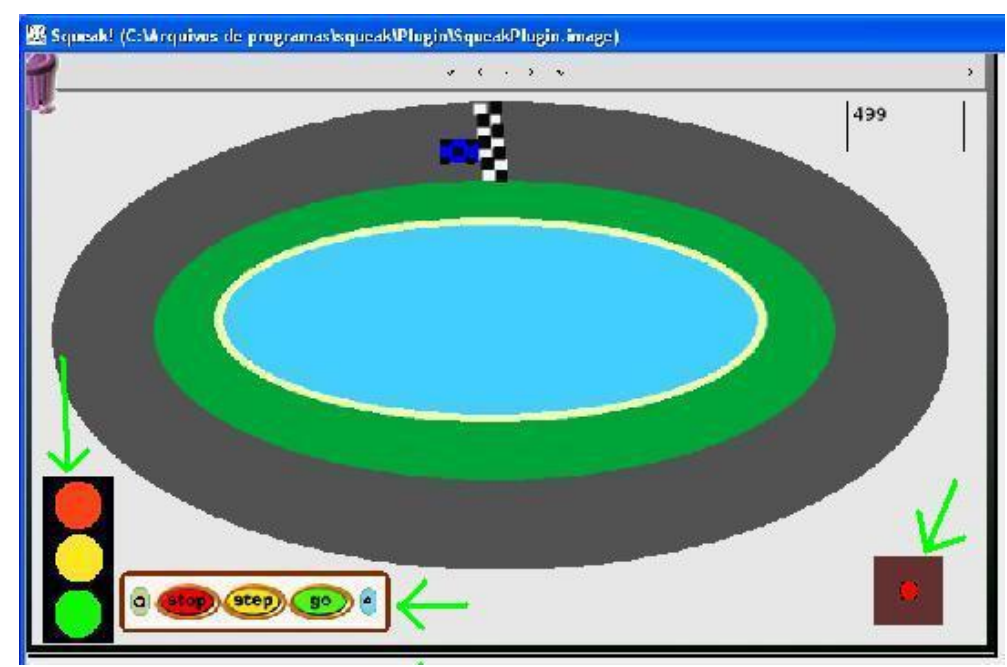

Figura 2. OA Rally dos sertões: roteiro de tela 03

\footnotetext{
${ }^{8}$ O Joystick é o objeto localizado no canto inferior direito da Figura 2 e sinalizado por uma seta verde
} 
Com relação à especificação de requisitos de programação, neste roteiro de tela foram necessárias duas codificações (scripts), conforme a Figura 3: uma para o objeto sinaleira (código à esquerda na figura) e outra para o objeto carrinho (código à direita na figura).

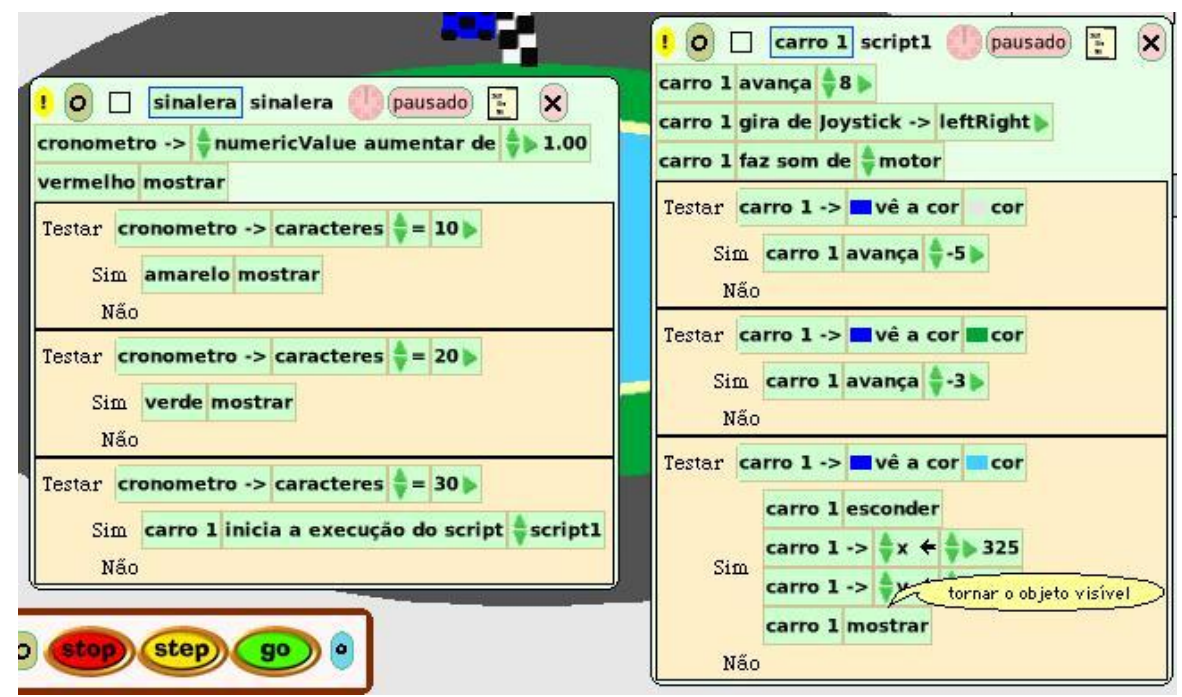

Figura 3. OA Rally dos sertões: trechos de programação

A lógica de programação utilizada no objeto sinaleira simula a ação de um semáforo que controla a largada de uma corrida. Este controle, para a troca de cores na sinaleira (vermelho, amarelo e verde), foi implementado com a utilização de um contador numérico, que é incrementado automaticamente em uma unidade. Para isso foi utilizado um objeto tipo texto (Suprimentos -> Catálogo de Objetos -> Texto -> Texto com borda), que representa este contador; após o contador ser iniciado, o objeto desenho, representando o sinal vermelho, torna-se visível, por meio do método $\operatorname{mostrar}^{9}$ (vermelho -> mostrar); na sequência utiliza-se de um teste SE (TESTE/SIM/NÃO), que controla o aparecimento de outras cores da sinaleira (amarelo e verde). Esse controle é feito comparando o conteúdo do contador com tempos prédefinidos em 10 e 20 unidades.

Após ser mostrado o sinal verde, uma nova codificação foi implementada para permitir a inicialização do script que controla o começo da corrida, onde o carro fica apto a ser guiado através do joystick. Para isso foi necessário utilizar-se do método "inicia a execução do script" (objeto $->$ inicia a execução do script $->$ script desejado). O script inicializado é o comentado a seguir (script no lado direito da Figura 3).

$\mathrm{O}$ carrinho foi configurado para ficar em movimento contínuo no eixo $\mathrm{X}$, com velocidade constante, através do método avança (objeto -> avança -> valor). A partir deste momento, o controle da direção no eixo Y (esquerda, direita) fica a cargo do usuário através do objeto joystick. Enquanto o carrinho se movimenta, é emitido um som predefinido pelo usuário (som de motor) através do método "faz som de" (objeto -> faz som de $>$ motor). Conforme a proposta inicial deste OA, foram definidos alguns obstáculos: quando o carrinho sai da pista pelo lado externo e interno, sua velocidade é reduzida; quando o carrinho cai no lago, este retorna a sua posição de largada.

O controle de verificação sobre o carrinho saiu da pista (externo, interno e lago) é feito por meio de um teste SE, utilizando-se como condição o método "vê a cor" (objeto -> vê a cor) de comparação de cores (quando uma cor se sobrepõe a outra). A ação sair da pista, pelo lado externo, é a comparação da cor do objeto (azul escuro) com a cor do mundo (cinza); pelo lado interno, é a comparação cor da "grama" (verde), e, no lago, com a cor azul claro. O retorno à posição inicial de largada é feito pela seguinte lógica de programação: quando o carrinho entra no lago, é utilizado o método esconder (para dar a impressão de que o carrinho afundou); após, são modificados os valores dos eixos $\mathrm{X}$ e $\mathrm{Y}$, que irão colocar o carrinho na sua posição de largada; por fim, utiliza-se mostrar, que irá fazer o carrinho reaparecer no mundo.

\footnotetext{
${ }^{9}$ A propriedade mostrar serve para tornar visível um objeto no mundo Squeak
} 
Esse processo foi desenvolvido através do ambiente de autoria para usuário final, denominado de Squeak, que é um software de autoria open source, baseado na linguagem de programação Smalltalk. Este possui máquinas virtuais Squeak (SqueakVM) e pode ser executado em computadores independentemente do sistema operacional. O Squeak, como descrito por Allen-Conn e Rose, "é muito mais que um processador de textos - é um processador de idéias. É uma linguagem, uma ferramenta, um ambiente de criação de idéias" [27]. Para García, "[...] Squeak não é um programa, é um ambiente especial onde se executam programas com uma intenção fundamentalmente educativa; Squeak é um mundo para criar mundos" [28].

Por fim, esta descrição do roteiro de tela 03 demonstra os potenciais para aprendizagem relacionados a especificações de requisitos, programação de scripts e autoria de interfaces gráficas. Portanto, para o contexto da pesquisa - de alunos do primeiro ano do ensino médio - a alternativa adotada para a programação do objeto sinaleira que simula a ação de um semáforo que controla a largada de uma corrida, demonstrou a capacidade de solução de problemas, de expressão criativa e de desenvolvimento do pensamento lógico.

\section{Considerações Provisórias}

Inicialmente, destaca-se que a metodologia descrita nesse artigo foi decorrente de um processo de investigação iniciado em 2004, como parte integrante da tese de doutorado, e este processo in loco foi uma das principais contribuições desta. Com isso, foi possível verificar a necessidade de mudança do paradigma escolar vigente, que tem o foco no ensino, para o foco na aprendizagem. Isso acarreta mudança na pedagogia da escola, em sua estrutura curricular, em seus espaços e tempos. Sem essas mudanças, as tecnologias digitais, os projetos de aprendizagem, bem como a metodologia proposta, continuarão sendo "subutilizados" e consequentemente, não potencializarão o processo de aprendizagem. A conclusão é de que, juntamente com programas, projetos, ações e metodologias que envolvam a adoção e utilização de tecnologias digitais, faz-se necessário repensar a pedagogia da escola.

Outra consideração, decorrente da experiência com a Escola MC - de produção de objetos de aprendizagem pelos alunos -, está relacionada aos observáveis e possíveis lógicos a partir da interação do sujeito com um objeto de aprendizagem pronto (desenvolvido por programadores, especialistas, etc) e os observáveis e possíveis lógicos decorrentes da interação do sujeito com um objeto de aprendizagem que está sendo construído por ele próprio - mesmo que este OA não fique pronto (com uma versão funcional publicável). Em síntese, foi constatado que, enquanto o sujeito está interagindo com um objeto de aprendizagem "pronto" - mesmo que apresente características interacionistas -, o que predomina são os observáveis, ficando restritos os possíveis lógicos. Porém, em contrapartida, enquanto o sujeito está interagindo com um objeto de aprendizagem que ele está construindo, o que predomina é a formação dos possíveis lógicos, requisito indispensável para o desenvolvimento da aprendizagem e construção do conhecimento. Como descreve Piaget (1985, p.7), "não é suficiente mostrar que todo conhecimento novo resulta de regulações, de uma equilibração", pois "se poderá supor que mesmo o mecanismo regulador é hereditário", ou que pode resultar "de aprendizagens mais ou menos complexas".

Assim, o processo de autoria desencadeado por meio da metodologia proposta contribui de forma efetiva para a construção de novos possíveis lógicos - de potenciais para aprendizagem - "que o sujeito descobrirá por si mesmo". Enfim, conforme afirma Piaget, "é esse de fato o problema central da epistemologia construtivista: o da construção ou criação do que existia apenas em estado virtual do 'possível' e que o sujeito deverá atualizar" (1985).

Por fim, o processo de autoria do objeto de aprendizagem "OA Rally dos Sertões", representado minimamente no roteiro de tela 03 (Figura 3), demonstra que o aluno (com auxílio de programadores) pode ser autor através de um ambiente de autoria para usuário final (neste caso o Squeak) de situações-problema significativas para si.

\section{Referências}

[1] PIAGET, J. Epistemologia genética. Tradução Álvaro Cabral. São Paulo: Martins Fontes, 1990 (Universidade Hoje). 
[2] MARASCHIN, C.; NEVADO, R. A. O paradigma epistemológico e o ambiente de aprendizagem Logo. In: Informática na Escola: pesquisas e experiências. Léa da Cruz Fagundes (Org.). Brasília: MEC/SEMTEC, 1994. p. 143-4)

[3] PIAGET, J.; GRÉCO, P. Aprendizagem e conhecimento. Tradução equipe da Livraria Freitas Bastos. Rio de Janeiro: Freitas Bastos, 1974.

[4] PIAGET, J. A equilibração das estruturas cognitivas: problema central do desenvolvimento. Tradução de Marion Merlone dos Santos Penna. Rio de Janeiro: Zahar, 1976. p. 11.

[5] PIAGET, J. O possível e o necessário: evolução dos possíveis na criança. Tradução de Bernardina Machado de Albuquerque. Porto Alegre: Artes Médicas, 1985. v.1. 137p.

[6] NEVADO, R. A. Espaços interativos de construção de possíveis: uma nova modalidade de formação de professores. 2001. Tese (Doutorado em Informática na Educação) - Universidade Federal do Rio Grande do Sul, Porto Alegre, 2001.

[7] PIAGET, J. O possível, o impossível e o necessário: as pesquisas em andamento ou projetadas no Centro Internacional de Epistemologia Genética. In: LEITE, Banks Luci; MEDEIROS, Ana A. de (Orgs.). Piaget e a Escola de Genebra. São Paulo: Cortez, 1987. p. 51-71.

[8] LOURENÇO FILHO, M. B. Introdução ao estudo da escola nova: bases, sistemas e diretrizes da pedagogia contemporânea. 12. ed. São Paulo: Melhoramentos, 1978.

[9] BARBOSA, M. C. S. Trabalhando com projetos na educação infantil. In: DALLA ZEN, M. I. H.; XAVIER, M. L. M. (Org.). Planejamento em destaque: análises menos convencionais. 2. ed. Porto Alegre: Mediação, 2000. p. 75-96.

[10] SNYDERS, G. Pedagogia progressista. Coimbra: Livraria Almedina, 1974.

[11] SAVIANI, D. Escola e democracia: polêmicas do nosso tempo. 36. ed. rev. Campinas: Autores Associados, 2003

[12] LIBÂNEO, J. C. Democratização da escola pública: a pedagogia crítico-social dos conteúdos. 3. ed. São Paulo: Edições Loyola, 1986.

[13] HERNÁNDEZ, F. Transgressão e mudança na educação: os projetos de trabalho. Porto Alegre: ArtMed, 1998.

[14] FAGUNDES, L. da C. et al. Aprendizes do futuro: as inovações começaram. Brasília: MEC/SEED/ProInfo, 1999. (Coleção Informática para a mudança na Educação)

[15] WILEY, D. A. Connecting learning objects to instructional design theory: a definition, a metaphor, and a taxonomy. In: WILEY, David A. (Ed.). The instructional use of learning objects: online version. 2001. Disponível em: <http://reusability.org/read/chapters/wiley.doc $>$.

[16] RITZHAUPT, A. D. Learning object system for the delivery of quality education. Disponível em: $<$ http://www.unf.edu/ rita0001/research/ learning_objects.pdf $>$.

[17] HODGINS, H. W. The Future of Learning Objects. In: WILEY, David A. (Ed.). The instructional use of learning objects: online version. 2001. Disponível em: $<$ http://reusability.org/read/chapters/hodgins.doc $>$.

[18] LTSC, LEARNING TECHNOLOGY STANDARDS COMMITTEE. Draft standard for learning object metadata (IEEE 1484.12.1-2002). New York: IEEE, 2002. Disponível em: $<\mathrm{http}: / /$ ltsc.ieee.org/wg12/files/LOM_1484_12_1_v1_Final_Draft.pdf $>$. 
[19] WISCONSIN ON-LINE RESOURCE CENTER. What are learning objects? 2000. Disponível em: $<$ http://www.wisc-online.com/Info/FIPSE-WhatisaLearningObject.htm>.

[20] WILEY, D. A. Connecting learning objects to instructional design theory: a definition, a metaphor, and a taxonomy. In: WILEY, David A. (Ed.). The instructional use of learning objects: online version. 2001. Disponível em: <http://reusability.org/read/chapters/wiley.doc $>$.

[21] L'AlLIER, J. J. Frame of Reference: NETg's Map to the products, their structure and core beliefs. NETg.1997. Disponível em: <http://www.im.com.tr/framerefer.htm>.

[22] THE MASIE CENTER. Making sense of learning specifications \& standards: a decision maker's guide to their adoption. 2. ed. 2003.

[23] SILVA, J. T. et al. Aprendendo as leis de Newton com os carrinhos de rolimã. Renote, v. 4, n. 2, dez. 2006.

[24] SILVA, J. T. da; FAGUNDES, L. da C.; BASSO, M.V. Metodologia para apoiar o processo de aprendizagem através da produção de objetos de aprendizagem. In: SÁNCHEZ, Jaime (Ed.). Nuevas ideas en informática educativa: Memorias del XII TISE. Volumen 3. Santiago de Chile: LOM Ediciones, 2007. p. 297-320.

[25] SILVA, J. T. da; FAGUNDES, L. da C.; BASSO, M.V. Metodologia de apoio ao processo de aprendizagem via autoria de objetos de aprendizagem por alunos. Renote, v. 6, n. 1, jul. 2008.

[26] PAPERT, S. A máquina das crianças: repensando a escola na era da informática. Tradução Sandra Costa. Porto Alegre: Artes Médicas, 1994.

[27] ALLEN-CONN, B. J.; ROSE, K. Ideas poderosas en el aula: el uso de Squeak para la mejora del aprendizaje de las matematicas y de las ciencias. Glendale-California: Viewpoints Research Institute, 2003.

[28] GARCÍA, J. R. F. A ferramenta que trará a revolução educativa. Linux Magazine, n. 16, maio 2006. (Tradução EscolaBR). 